\title{
The Role of Mother's Knowledge, Attitudes, Practices in Dental Caries on Vulnerably Preschool Children
}

\author{
Patrícia Blaya Luz ${ }^{1}$, Joanna Tatith Pereira ${ }^{\circledR}$, Jessica Klöckner Knorst²® ${ }^{\circledR}$, Inaiá Bonfadini1 ${ }^{\circledR}$,

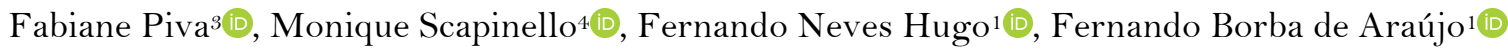

\begin{abstract}
${ }^{1}$ Department of Pediatric Dentistry, Faculty of Dentistry, Federal University of Rio Grande do Sul, Porto Alegre, RS, Brazil.

2Department of Stomatology, School of Dentistry, Federal University of Santa Maria, Santa Maria, RS, Brazil.

${ }^{3}$ School of Dentistry, Lutheran University of Brazil, Canoas, RS, Brazil.

${ }^{4}$ Institute of Psychology, Federal University of Rio Grande do Sul, Porto Alegre, RS, Brazil.
\end{abstract}

Author to whom correspondence should be addressed: Joanna Tatith Pereira, Rua Joana Dar'c, 488, Nossa Senhora de Lourdes, Santa Maria, RS, Brazil. 97060-360. Phone: + 5551981714591. E-mail: contato@joanna.odo.br.

Academic Editors: Alessandro Leite Cavalcanti and Wilton Wilney Nascimento Padilha

Received: 15 March 2019 / Accepted: 17 October 2019 / Published: 25 October 2019

How to cite this article: Luz PB, Pereira JT, Knorst JK, Bonfadini I, Piva F, Scapinello M, Hugo FN, Araújo FB. The role of mother's knowledge, attitudes, practices in dental caries on vulnerably preschool children. Pesqui Bras Odontopediatria Clín Integr. 2020; 20:e4687. https://doi.org/10.1590/pboci.2020.007

\begin{abstract}
Objective: To analyze the association between Early Childhood Caries (ECC) and mother's knowledge, attitudes, and practices (KAP). Material and Methods: This cross-sectional study included a random sample of 163 preschool children aged 3-4 old in southern Brazil. The severity of dental caries and ECC was assessed by ICDAS criteria, while mothers completed the semi-structured questionnaire (KAP-ECC). Maternal behavior characteristics and answered questions about socioeconomic and demographic variables. Logistic regression was performed to evaluate the association of exploratory variables with ECC. For this approach, we calculated the odds ratio (OR) and 95\% confidence intervals (95\% IC). Results: Dental examinations revealed that $91.4 \%$ of children presented $\mathrm{ECC}$ (ICDAS $=3,4,5$ or 6 ). Among those children, $31.9 \%$ presented cavities (ICDAS $\geq 3$ ). Family income was significantly associated with the presence of ECC (OR 2.17; 95\% CI: 1.41-3.36). Regarding KAP-ECC, mothers have knowledge related to ECC etiology, reported dental hygiene attitudes and practices that can prevent ECC but reported less healthy attitudes and practices regarding child's diet, specifically with respect to bottle and breastfeeding habits (OR 0.52; 95\% CI: 0.33-0.81). Conclusion: ECC was more frequent in children from low-income families and whose mothers reported the belief that milk with chocolate does not contribute to caries and that disagreed that it is normal that a 2-year-old baby wakes up during the night to suckle. That is, good knowledge toward health habits may impact on lower occurrence of ECC; however, this condition also depends on the socioeconomic level.
\end{abstract}

Keywords: Cross-Sectional Studies; Dental Caries; Maternal Behavior; Socioeconomic Factors. 


\section{Introduction}

The prevalence of caries has declined in recent years [1]; however, the apparent decline does not mean that this is no longer a public health problem. The decline of caries experience in several countries has been accompanied by a process of inequality in the distribution of the disease, especially those individuals who remain on the fringes of society [1,2]. Thus, dental caries is prevalent worldwide and is a public health problem in many countries [1,3,4], including Brazil [2,5]. The most recent epidemiological survey performed in Brazil reports that more than half of 5-year-old children have experience of early childhood caries (ECC) $[5]$.

Previous studies have indicated low maternal education and low income as risk factors for ECC [6-9]. Moreover, poor dietary habits and dental hygiene practices have also been associated with ECC [9-12]. The presence of ECC has also been associated with subjective aspects of health, such as oral health related quality of life (OHRQoL). The presence of ECC influenced negatively children's OHRQoL [13], in this way, being a disease of great impact in the life of the children. It is unquestionable that social susceptibility plays a role in the ECC etiology $[10,11,14,15]$. The question that remains is if the mothers do know the ECC etiological factors and cannot establish preventive attitudes and practices or they do not know it.

In this sense, to find it out is important to know the individual level as well as the social circumstances wherein the individual is inserted. The individual level involves beliefs, behavior, psychological aspects, and routine habits [14]. The circumstances involve the whole environment: house, family constitution, job, public transport, public health and interpersonal relationship, usually accesses by socioeconomic status [14]. In this context, it fits a Knowledge, Attitudes and Practices (KAP). KAP is an instrument used to collect information on what is known, believed and done in relation to a particular topic - in this case, ECC [16].

Thus, understand the role of the mother's knowledge, attitudes, and practices in early childhood caries can provide support for the creation of public health policies focused on determinants. The aim of the study was to analyze the association between ECC and KAP-ECC. We hypothesized that children whose mothers had poor knowledge, attitudes and practices regarding ECC are more likely to have dental caries.

\section{Material and Methods}

Study Design and Subjects

This cross-sectional study included 163 preschools born in 2008 in Porto Alegre, a southern city in Brazil. All 674 children born in 2008 (3-4-year-old) and registered in one of the GHC Community Health Units were eligible. The GHC is constituted by one hospital and 12 Primary Care Services distributed in the north area of Porto Alegre, RS-Brazil (city with 1,5 million inhabitants). GHC is part of the Ministry of Health, attends exclusively patients from the Brazilian Public Health Service and it is known nationality because it is the biggest network of public health in the south of Brazil.

The sample size was calculated considering the number of births in these communities in $2008(674$ infants) and a prevalence of $31 \%$ in the exposed group (with caries - ECC at two years) [6]. The ratio of exposed to unexposed was 1:1, sampling error of $5 \%$ and $95 \%$ confidence level (CI). Considering possible losses, $20 \%$ was added to the sample size, resulting in a required minimum of 208 dyads of mother-child. The sample selection was randomly performed using a table with random numbers maintaining the proportion of children born in each Primary Care Service. The exclusion criterion was: children/mother with cognitive diseases. 


\section{Data Collection}

Three dentists (PBL, JTP, IB) carried out all the dental examination and applied all questionnaires helped by an undergraduate student (MS). Data collection was conducted from December 2011 to January 2013, including structured interviews conducted with the mothers and clinical examination of the children. The calibration was performed at the Pediatric Dentistry Ambulatory of the Federal University of Rio Grande do Sul. Ten children were examined and re-examined two weeks later. The tooth surface was considered as the unit analysis for Kappa calculation. A pilot study of 30 pairs of children and mothers (who were not part of the sample) was carried out to test the methodology and the understanding of questionnaires used.

All data collection was performed at the participants' homes, using the available house facilities, such as sofas, chairs and tables. A phone call previously set the appointment. Families that phone numbers did not match were directly visited and if there was nobody at home, a letter was left explaining the study and asking people to contact the researchers by telephone. This procedure was repeated at least three times, in different days and times, before the family was considered non-respondent.

The severity of dental caries experience was assessed by ICDAS criteria. Even the three dentists being already familiar to ICDAS, they were trained previously using an E-learning Program [17]. According to ICDAS protocol, all two examinations were performed with a dental surface clean, illuminated and dry $[18,19]$. Prophylaxis was conducted with toothbrushes and dental floss. After that, the dental examination was conducted using the house facilities and portable resources: air compressor, suction device, headlight, WHO probe, tweezers, dental mirror and cotton rolls. All personal equipment for biosecurity was always used.

One of the dentists dictated ICDAS codes to the undergraduate student who recorded it in a paper form. For each dental surface, a code for dental condition (presence and type of restorations) and a code for caries status were recorded and afterward the caries conditions of the teeth were categorized according to the worse surface code. The criterion used to dichotomize presence/absence of ECC for the association analysis was based on WHO recommended caries index - dmft: ICDAS 0, 1, $2=$ no ECC and ICDAS $3,4,5$ or $6=$ presence of $\mathrm{ECC}[20]$.

Mothers' knowledge, attitudes and practices were collected through the KAP questionnaire [16]. KAP is an instrument used to collect information on what is known, believed and done in relation to a particular topic - in this case, ECC. In order to test the applicability, understanding and the time taken to answer all the KAP questions, a pilot study was conducted in another $r$ region of Porto Alegre during a vaccination campaign. Sixty-eight mothers participated in the pilot study. Some modifications in KAP were performed, such as reducing the numbers of possible answers in Attitudes (from 5 to 3) [16].

KAP - ECC questionnaire is divided into three parts: (1) Knowledge: shows if mothers have basic knowledge about dental caries and its etiological factors. Nine sentences about caries issues were presented. The participant could choose only one of these three answers options: “yes”, “no” or “don’t know”; (2) Attitudes: Reveals the way mothers act regarding her child's dietary and dental care. It shows how the mother understands her role in different daily situations. It is more related to the kind of position she assumes in her child's health. It is evaluated through mother/child life situations sentences wherein the mother can choose between "agree", "disagree” and "neither agree or disagree”; (3) Practices: dietary habits and dental hygiene habits are presented in a "How Often You (...)" kind of question. The possibilities of answers are: "always", "frequently", "sometimes", "rarely" and "never". The answers were dichotomized for the analysis.

Demographic and socioeconomics characteristics including: sex (male or female), primary caretaker (dichotomized in mother or father/grandmother), household income, income satisfaction (yes or no), mothers' 
age, maternal education, number of sons, number of people living in the house, marital status and mother's job status. Household income was a sum of all forms of income in a month. It was collected in Reais (Brazilian cure - $\mathrm{R} \$ 3.75$ it was equivalent to $\mathrm{U} \$ 1.00$ approximately) and categorized as the Brazilian minimum wages (BMW): $\leq 2,>2 \leq 5$, or $>5$ times the BMW. Maternal education was collected in years of study and categorized as Primary education (<9 years), Secondary education (9-11 years) or Tertiary education (>11 years). Mother' age was dichotomized and $<32$ or $>32$. The number of sons was dichotomized in $<2$ or $>5$. The amount of individuals in the house were evaluated through the number of people living in the house and categorized according to the median $(\leq 4$ people, or $>4$ ). The marital status was dichotomized in not married or married. The mother's job status was evaluated in yes or no.

\section{Statistical Analysis}

All data were analyzed using SPSS 20.0 version (IBM SPSS, Chicago, IL, USA). Continuous variables were described by means and standard deviation $(\mathrm{SD})$ and the categorical variables were described as absolute numbers and relative percentages. The associations between the outcome and the independent variables were tested using the Chi-squared test (for categorical variables) and the T Student test (for parametric continuous variables). Logistic regression was performed to evaluate the association of exploratory variables with ECC. All variables that had $\mathrm{p}<0.20$ in the crude analyses were included in the final model. From this comparison, a fully adjusted model was obtained. Odds ratio (OR) and respective 95\% confidence intervals (CI) of the exposures in relation to the outcomes are shown.

Ethical Aspects

Ethical approval was obtained from the Human Ethical Committee of Conceição Hospital Group (GHC) (CEP-GHC/11-196). Signed informed consent was obtained from mothers prior to the beginning of the study. This study is reported according to STROBE (Strengthening the Reporting of Observational Studies in Epidemiology) guidelines.

\section{Results}

A total of 163 mother-child agreed to participate of the study (78.4\% response rate). Eleven families did not agree to participate and the principal reason for refusal was lack of time. We collected SES data from 8 of those 11 families, and they were not different from the mean of participants, regarding age, income and education. The mean inter and intraexaminer Kappa value for dental caries was 0.67 (ranging from 0.64 to 0.73 ) and 0.78 (ranging from 0.75 to 0.80 ), respectively.

The frequency of SES predictor variables and their relation to ECC of the sample are shown in Table 1. Most of the children with ECC were girls (51.9\%) and from low-income families (61.5\%). Dental examinations revealed that $91.4 \%$ of children presented ECC, considering the presence of white spots (ICDAS code 1). Enamel lesions (ICDAS 1, 2 and 3) were responsible for 68.1\%, while dentin lesions (ICDAS 4, 5 and 6 ) represented $23.3 \%$ of caries detected. Among those children, $31.9 \%$ presented cavities (ICDAS $\geq 3$ ). The ICDAS severity ranged from 0 to 6 and the mean was 2.54 (SD 1.57).

Association between knowledge, attitudes and practices variables and ECC are presented in Table 2. Bivariate analyses showed that mothers of caries-free children answered correctly more frequently that industrialized juices can contribute to caries $(p=0.005)$. The same was observed with respect to chocolate milk consumption $(\mathrm{p}=0.041)$. Attitudes questions demonstrated that mothers whose children presented ECC 
believed more frequently that a $2 \mathrm{y}$-old baby wakeup during the night to be bottle-fed was normal $(\mathrm{p}=0.001)$. They also agreed that the only way to stop their child crying was by offering milk more frequently $(p=0.028)$. Results pertaining to dietary practices showed that mothers fed children that had ECC with sugary beverages more frequently $(p=0.034)$. Furthermore, children with ECC were breastfed for more than two years more frequently than caries free ones $(\mathrm{p}=0.031)$.

Table 1. Frequency of SES predictor variables and their relation to ECC.

\begin{tabular}{|c|c|c|c|}
\hline Variables & $\begin{array}{c}\text { ECC Free } \\
\mathrm{N}(\%)\end{array}$ & $\begin{array}{c}\text { ECC Present } \\
\mathrm{N}(\%)\end{array}$ & p-value* \\
\hline \multicolumn{4}{|l|}{ Sex } \\
\hline Male & $49(44.1)$ & $25(48.1)$ & 0.638 \\
\hline Female & $62(55.9)$ & $27(51.9)$ & \\
\hline \multicolumn{4}{|l|}{ Primary Caretaker } \\
\hline Mother & $108(97.3)$ & $49(94.2)$ & $0.385^{\mathrm{b}}$ \\
\hline Father/Grandmother & $3(2.7)$ & $3(5.8)$ & \\
\hline \multicolumn{4}{|l|}{ Mothers Age } \\
\hline$\leq 32$ & $53(47.7)$ & $24(46.2)$ & 0.849 \\
\hline$>32$ & $58(52.3)$ & $28(53.8)$ & \\
\hline \multicolumn{4}{|l|}{ Education } \\
\hline Primary & $25(22.5)$ & $15(28.8)$ & 0.594 \\
\hline Secondary & $49(44.1)$ & $23(44.3)$ & \\
\hline Tertiary & $37(33.4)$ & $14(26.9)$ & \\
\hline \multicolumn{4}{|l|}{ Marital Status } \\
\hline Single/Divorced & $41(36.9)$ & $18(34.6)$ & 0.774 \\
\hline Married & $70(63.1)$ & $34(65.4)$ & \\
\hline \multicolumn{4}{|c|}{ Mother Worked During the First Two Years of Child's Life } \\
\hline Yes & $70(63.1)$ & $27(51.9)$ & 0.177 \\
\hline No & $41(36.9)$ & $25(48.1)$ & \\
\hline \multicolumn{4}{|l|}{ Household Income } \\
\hline$\leq 2 \mathrm{BMW}^{\mathrm{a}}$ & $24(21.6)$ & $32(61.5)^{\dagger}$ & $<0.001^{\mathrm{c}}$ \\
\hline$>2 \leq 5 \mathrm{BMW}$ & $63(56.8)$ & $16(30.8)$ & \\
\hline$>5 \mathrm{BMW}$ & $24(21.6)$ & $4(7.7)$ & \\
\hline \multicolumn{4}{|l|}{ Income Satisfaction } \\
\hline Yes & $53(47.7)$ & $20(37.3)$ & 0.212 \\
\hline No & $58(52.3)$ & $32(62.7)$ & \\
\hline \multicolumn{4}{|l|}{ Number of People Living at Home } \\
\hline$\leq 4$ People & $60(54.1)$ & $22(42.3)$ & 0.161 \\
\hline$>4$ People & $51(45.9)$ & $30(57.7)$ & \\
\hline \multicolumn{4}{|l|}{ Number of Son/Daughter } \\
\hline$\leq 2$ & $78(70.3)$ & $36(69.2)$ & 0.893 \\
\hline$>5$ & $33(29.7)$ & $16(9.8)$ & \\
\hline
\end{tabular}

Values lower than 163 due to missing data; *Chi-square Test; aBMW: Brazilian Minimum Wages; ${ }^{\text {} F i s c h e r ~ E x a c t ~ T e s t ; ~ ' K r u s k a l-W a l l i s ~}$ test.

Table 2. Association between knowledge, attitudes and practices variables and ECC.

\begin{tabular}{|c|c|c|c|}
\hline Variables & $\begin{array}{c}\text { ECC Free } \\
\mathrm{N}(\%)\end{array}$ & $\begin{array}{c}\text { ECC Present } \\
\mathrm{N}(\%)\end{array}$ & p-value* \\
\hline \multicolumn{4}{|l|}{ Knowledge } \\
\hline Bad Performance & $76(46.6)$ & $34(20.9)$ & 0.722 \\
\hline Good Performance & $35(21.5)$ & $18(11.0)$ & \\
\hline \multicolumn{4}{|l|}{ Bottle Juice } \\
\hline Does not Contribute to Caries & $17(10.4)$ & $18(11.0)$ & 0.005 \\
\hline Contributes to Caries & $94(57.7)$ & $34(20.9)$ & \\
\hline \multicolumn{4}{|l|}{ Milk with Chocolate } \\
\hline Does not Contribute to Caries & $5(3.1)$ & $7(4.3)$ & 0.041 \\
\hline Contributes to Caries & $106(65.0)$ & $45(27.6)$ & \\
\hline
\end{tabular}

Attitudes 
The Only Way to Stop my Child Crying is Offering Milk (Breast/Bottle)? Disagree Agree

Sounds Normal a 2y-old Baby Wakeup During the Night to Bottle Feed Disagree Agree

$95(85.6) \quad 39(75) \quad 0.028$ $16(14.4) \quad 13(25)$

$82(73.9) \quad 24(46.2) \quad 0.001$

$29(26.1) \quad 28(53.8)$

Practices

What is the Liquid that Your Child Most Drinks During the Day?

Sugar Free (Water/Pure Milk)

With Sugar (Soda/Bottle Juice)

Breastfeeding Time

Did not Breast Feed or Did Until 2 Years Old

More than 2 years

*Chi-square Test.

Table 3 showed the adjusted association of exploratory variables with ECC. That family income was significantly associated with the presence of ECC (OR 2.17; 95\% CI: 1.41-3.36). Regarding maternal knowledge, the belief that milk with chocolate does not contribute to caries remained significantly associated with ECC (OR 1.88; 95\% CI: 1.11-3.20). Regarding mothers' attitudes, disagreeing that is normal that a 2year-old baby wakes up during the night to bottle-feed was independently associated with the outcome (OR 0.52; 95\% CI: 0.33-0.81).

Table 3. Unadjusted and adjusted association of exploratory variables with ECC determined using logistic regression.

\begin{tabular}{|c|c|c|c|c|}
\hline \multirow{2}{*}{ Variables } & \multicolumn{2}{|c|}{ Unadjusted } & \multicolumn{2}{|c|}{ Adjusted } \\
\hline & $\mathrm{OR}^{\mathrm{a}}\left(95 \% \mathrm{CI}^{\mathrm{b}}\right)$ & p-value & OR $(95 \% \mathrm{CI})$ & p-value \\
\hline \multicolumn{5}{|l|}{ Socioeconomic } \\
\hline \multicolumn{5}{|l|}{ Household Income } \\
\hline$\leq 2 \mathrm{BMWc}^{\mathrm{c}}$ & $4.00(1.57-10.19)$ & 0.004 & $2.17(1.41-3.36)$ & $<0.001$ \\
\hline$>2 \leq 5 \mathrm{BMW}$ & $1.41(0.51-3.88)$ & 0.497 & - & \\
\hline$>5 \mathrm{BMW}$ & 1.0 & & 1.0 & \\
\hline \multicolumn{5}{|c|}{ Mother's Working Situation Outside Home? } \\
\hline Yes & $0.73(0.47-1.14)$ & 0.175 & - & \\
\hline No & 1.0 & & & \\
\hline \multicolumn{5}{|l|}{ Number of People Living at Home } \\
\hline$\leq 4$ People & $0.72(0.45-1.14)$ & 0.166 & - & \\
\hline$>4$ People & 1.0 & & & \\
\hline \multicolumn{5}{|l|}{ Knowledge } \\
\hline \multicolumn{5}{|l|}{ Bottle Juice } \\
\hline Does not Contribute to Caries & $1.93(1.25-2.98)$ & 0.003 & - & \\
\hline Contributes to Caries & 1.0 & & & \\
\hline \multicolumn{5}{|l|}{ Milk with Chocolate } \\
\hline Does not Contribute to Caries & $1.95(1.14-3.35)$ & 0.014 & $1.88(1.11-3.20)$ & 0.019 \\
\hline Contributes to Caries & 1.0 & & 1.0 & \\
\hline
\end{tabular}

Attitudes

The Only Way to Stop my Child Crying is Offering

Milk (Breast/Bottle)?
Disagree
Agree
$0.64(0.40-1.05)$
0.79
1.0
Sounds Normal a 2y-old Baby Wakeup During the
Night to Bottle Feed
Disagree
Agree
$0.46(0.29-0.71)$
0.001
$0.52(0.33-0.81)$
0.004
1.0
1.0

Practices

What is the Liquid that Your Child Most Drinks

During the Day? 


\begin{tabular}{|c|c|c|c|}
\hline Sugar Free (Water/ Pure Milk) & $0.560 .35-0.89)$ & 0.015 & - \\
\hline With Sugar (Soda/Bottle Juice) & 1.0 & & \\
\hline \multicolumn{4}{|l|}{ Duration of Breastfeeding? } \\
\hline Did not Breast Feed or Did Until 2 Years Old & $0.61(0.38-0.97)$ & 0.040 & - \\
\hline More Than 2 Years Old & 1.0 & & \\
\hline
\end{tabular}

aR: Odds Ratio; ${ }^{\mathrm{b} C I}$ : Confidence Interval; ${ }^{\mathrm{c} B M W: ~ B r a z i l i a n ~ M i n i m u m ~ W a g e s . ~}$

\section{Discussion}

The findings support in part the hypothesis that mothers' KAP regarding ECC influence children's dental caries. Children who presented ECC in the form of cavitated lesions were significantly associated with the mothers' negative attitudes and knowledge. Similarly, low household income also associated with the presence of dental caries in preschool children. Understanding these associations may lead to a broader view of the aspects that influence children's ECC, especially socially vulnerable.

Parental factors, such as knowledge, attitudes and behaviors strongly influence their children's behavior and health [21]. In this study, we assessed first the effect of mothers' oral health KAP on ECC. The results showed that mothers are aware of the basic knowledge about ECC, they generally have positive dental hygiene attitudes and practices that can prevent ECC, but they reported less healthy attitudes and practices regarding children's diet. Maybe the basic knowledge that the majority of mothers showed was not enough to make them choose healthier decisions

ECC was more frequent in children whose mothers reported the belief that milk with chocolate does not contribute to caries. This possible explanation for these findings is that by avoiding milk with chocolate, mothers buy industrialized juices hoping that it is a healthier option [15,23]. Unfortunately, industrialized juices have high amounts of added sugars. In Brazil, industrialized juices became recently very popular because they represent a cheap and convenient alternative to natural juices. In addition, they are presented as healthy beverages in the advertisements. However, those juices usually are very acid, with a high sugar content, which contributes to caries [15,23].

Children whose mothers disagreeing that it is normal that a 2-year-old baby wakes up during the night to suckle were protected from caries. That is, children whose mothers had this habit were more likely to have ECC. To many mothers of children with ECC, it sounded that a 2 years-old child wakes up during the night to nurse is normal. This action is not directly related to ECC because we did not say that the content of the bottle was cariogenic. However, it reveals a habit that can contribute to caries development and that maybe the mother cannot remember clearly. A 2-year-old child is able to have all the food needed during the day and rest the whole night [24]. The problem is if the child is used to nurse during the night, and their parents think it is normal, they will keep with this unhealthy routine and this can end up favoring the demineralization process. Again, the environment plays a role in ECC etiology. Furthermore, frequent night feeding may have a greater impact on caries development, due to a low salivary flow rate during sleep time and increased contact time of plaque and substrates [25].

Besides that, children from low-income families also were more likely to have dental caries, in accordance with previous studies [26-34]. Income can affect ECC etiological chain thru different ways. A possible explanation for this is that individuals with poor socioeconomic status are more susceptible to general and oral health risk factors [31]. Those people usually have fatalist beliefs and poor self-perception of health, which results in poor self-care [35]. Moreover, health literacy is "the degree to which individuals have the capacity to obtain, process, and understand basic health information and services needed to make appropriate health decisions" [36,37]. In addition, the families evaluated in this study are covered by Public Primary 
Health Care Services, thus, mostly middle and low-income families. Thus, even mothers knowing about healthier choices, they could not opt for them, since they are the most expensive. Living under vulnerable conditions makes it difficult to buy proper food, to buy hygiene items, to have a satisfactory house [35].

Our study has some limitations. The cross-sectional design prevents the establishment of causality between variables. We also acknowledge as a study limitation the limited sample size, but this was due to the sampling strategy, i.e., participants were sampled in their homes. Moreover, recall bias may impact results to some extent. Nevertheless, this study also has strengths. The findings obtained through the ICDAS show more realistic ECC distribution when compared with the widely used DMFT [20]. In addition, the ICDAS has been previously used in other epidemiological surveys with children [20,35-38].

\section{Conclusion}

Early-Childhood-Caries was more frequent in children from low-income families and whose mothers reported the belief that milk with chocolate does not contribute to caries and that disagreed that it is normal that a 2 -year-old baby wakes up during the night to suckle. That is, good knowledge toward health habits may impact the lower occurrence of ECC; however, this condition also depends on the socioeconomic level. These findings meaning that healthy nutrition programs may provide additional benefits in terms of healthier dentition in young children. Understanding these associations may lead to a broader view of the aspects that influence children's ECC, especially in socially vulnerable.

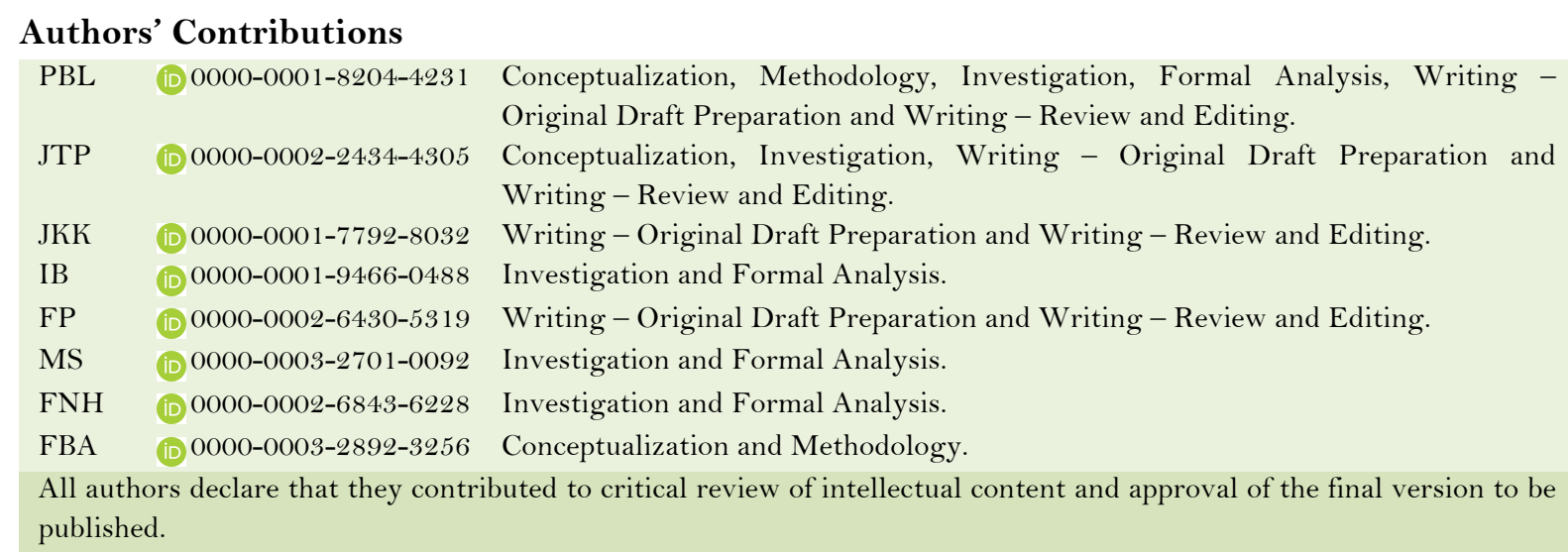

\section{Financial Support}

This article is part of a bigger project financed with funds granted by the Universal Public Notice - CNPQ (Grant No. 479894/2010-8), Researcher Gaucho Public Notice - FAPERGS (Grant No. 111368-4) and by the Higher Education Personnel Improvement Coordination (CAPES).

\section{Conflict of Interest}

None.

\section{References}

[1] Gimenez T, Bispo BA, Souza DP, Viganó ME, Wanderley MT, Mendes FM, et al. Does the decline in caries prevalence of Latin American and Caribbean children continue in the new century? evidence from systematic review with meta-analysis. PLoS One 2016; 11(10):e0164903. https://doi.org/10.1371/journal.pone.0164903

[2] Ardenghi TM, Piovesan C, Antunes JL. Inequalities in untreated dental caries prevalence in preschool children in Brazil. Rev Saúde Pública 2013; 47(Suppl 3):129-37. https://doi.org/10.1590/s0034-8910.2013047004352 
[3] Marcenes W, Kassebaum NJ, Bernabé E, Flaxman A, Naghavi M, Lopez A, et al. Global burden of oral conditions in 1990-2010: a systematic analysis. J Dent Res 2013; 92(7):592-7. https://doi.org/10.1177/0022034513490168

[4] Kassebaum NJ, Bernabé E, Dahiya M, Bhandari B, Murray CJ, Marcenes W. Global burden of untreated caries: a systematic review and metaregression. J Dent Res 2015; 94(5):650-8. https://doi.org/10.1 177/0022034515573272

[5] Brasil. Ministerio da Saude. Pesquisa Nacional de Saúde bBucal. SB Brasil 2010. Resultados Principais. Brasília: Ministerio da Saúde; 2011; 92p. [In Portuguese].

[6] Ferreira SH, Beria JU, Kramer PF, Feldens EG, Feldens CA. Dental caries in 0- to 5-year-old Brazilian children: prevalence, severity, and associated factors. Int J Paediatr Dent 2007:17(4):289-96.

https://doi.org/10.1111/j.1365-263X.2007.00831.x

[7] Feldens CA, Kramer PF, Sequeira MC, Rodrigues PH, Vitolo MR. Maternal education is an independent determinant of cariogenic feeding practices in the first year of life. Eur Arch Paediatr Dent 2012; 13(2):70-5.

[8] Plonka KA, Pukallus ML, Barnett AG, Holcombe TF, Walsh LJ, Seow WK. A longitudinal case-control study of caries development from birth to 36 months. Caries Res 2013; 47(2):1 17-27. https://doi.org/10.1159/000345073

[9] Corrêa-Faria P, Paixão-Gonçalves S, Paiva SM, Pordeus IA, Marques LS, Ramos-Jorge ML. Association between developmental defects of enamel and early childhood caries: a cross-sectional study. Int J Paediatr Dent 2015; 25(2):103-9. https://doi.org/10.1111/ipd.12105

[10] Palmer CA, Kent R Jr., Loo CY, Hughes CV, Stutius E, Pradhan N, et al. Diet and caries-associated bacteria in severe early childhood caries. J Dent Res 2010; 89(11):1224-9. https://doi.org/10.1177/0022034510376543

[11] Slabsinskiene E, Milciuviene S, Narbutaite J, Vasiliauskiene I, Andruskeviciene V, Bendoraitiene EA, et al. Severe early childhood caries and behavioral risk factors among 3-year-old children in Lithuania. Medicina 2010; 46(2):13541.

[12] Wulaerhan J, Abudureyimu A, Bao XL, Zhao J. Risk determinants associated with early childhood caries in Uygur children: a preschool-based cross-sectional study. BMC Oral Health 2014; 14:136. https://doi.org/10.1186/1472-6831-14-136

[13] Chaffee BW, Rodrigues PH, Kramer PF, Vítolo MR, Feldens CA. Oral health-related quality-of-life scores differ by socioeconomic status and caries experience. Community Dent Oral Epidemiol 2017; 45(3):216-24. https://doi.org/10.1111/cdoe.12279

[14] Fisher-Owens SA, Gansky SA, Platt LJ, Weintraub JA, Soobader MJ, Bramlett MD, et al. Influences on children's oral health: a conceptual model. Pediatrics 2007; 120(3):e510-20. https://doi.org/10.1542/peds.2006-3084

[15] Seow WK. Environmental, maternal and child factors which contribute to early childhood caries: unifying conceptual model. Int J Paediatr Dent 2012; 22(3):157-68. https://doi.org/10.1111/j.1365-263X.2011.01186.x

[16] World Health Organization Stop TB Partnership. Advocacy, communication and social mobilization for TB control: a guide to developing knowledge, attitude and practice surveys. Geneva: World Health Organization, 2008;35p.

[17] Rodrigues JA, de Oliveira RS, Hug I, Neuhaus K, Lussi A. Performance of experienced dentists in Switzerland after an e-learning program on ICDAS occlusal caries detection. J Dent Educ 2013; 77(8):1086-91.

[18] Ekstrand KR, Martignon S, Ricketts DJ, Qvist V. Detection and activity assessment of primary coronal caries lesions: a methodologic study. Oper Dent 2007; 32(3):225-35.

[19] Ismail AI, Sohn W, Tellez M, Amaya A, Sen A, Hasson H, Pitts NB. The International Caries Detection and Assessment System (ICDAS): an integrated system for measuring dental caries. Community Dent Oral Epidemiol 2007; 35(3):170-8. https://doi.org/10.1111/j.1600-0528.2007.00347.x

[20] Mendes FM, Braga MM, Oliveira LB, Antunes JL, Ardenghi TM, Bonecker M. Discriminant validity of the International Caries Detection and Assessment System (ICDAS) and comparability with World Health Organization criteria in a cross-sectional study. Community Dent Oral Epidemiol 2010; 38(5):398-407. https://doi.org/10.1111/j.1600-0528.2010.00557.x

[21] Mitrakul K, Laovoravit V, Vanichanuwat V, Charatchaiwanna A, Bunpradit W, Arunakul M. Factors associated with parent capability on child's oral health care. Southeast Asian J Trop Med Public Health 2012; 43(1):249-55.

[22] Suma-Sogi HP, Hugar SM, Nalawade TM, Sinha A, Hugar S, Mallikarjuna RM. Knowledge, attitude, and practices of oral health care in prevention of early childhood caries among parents of children in Belagavi city: a Questionnaire study. J Family Med Prim Care 2016; 5(2):286-90.

[23] Seow WK. A nutritional program involving home visits may reduce the incidence of early childhood caries. J Evid Based Dent Pract 2011; 11(1):60-1. https://doi.org/10.1016/j.jebdp.2010.11.003

[24] Maguire JL, Birken CS, Jacobson S, Peer M, Taylor C, Khambalia A, et al. Office-based intervention to reduce bottle use among toddlers: TARGet Kids! Pragmatic, randomized trial. Pediatrics 2010; 126(2):e343-50. https://doi.org/10.1542/peds.2009-3583

[25] Firestone AR. Effect of increasing contact time of sucrose solution of powdered sucrose on plaque pH in vivo. J Dent Res 1982; 61(11):1243-4.

[26] Dini EL, Holt RD, Bedi R. Caries and its association with infant feeding and oral health-related behaviours in 3-4year-old Brazilian children. Community Dent Oral Epidemiol 2000; 28(4):241-8.

[27] Fadel CB, Saliba NA. Aspectos sócio-dentais e de representação social da cárie dentária no contexto materno-infantil. RGO 2009; 57:303-9. [In Portuguese]. 
[28] Hallett KB, O'Rourke PK. Social and behavioural determinants of early childhood caries. Aust Dent J 2003; 48(1):2733.

[29] Menon I, Nagarajappa R, Ramesh G, Tak M. Parental stress as a predictor of early childhood caries among preschool children in India. Int J Paediatr Dent 2013; 23(3):160-5. https://doi.org/10.1111/j.1365-263X.2012.01238.x

[30] Nunn ME, Braunstein NS, Krall Kaye EA, Dietrich T, Garcia RI, Henshaw MM. Healthy eating index is a predictor of early childhood caries. J Dent Res 2009; 88(4):361-6. https://doi.org/10.1177/0022034509334043

[31] Freire MCM, Reis SC, Figueiredo N, Peres KG, Moreira RS. Antunes JL. Individual and contextual determinants of dental caries in Brazilian 12-year-olds in 2010. Rev Saúde Pública 2013; 47(3):40-9. https://doi.org/10.1590/s0034-8910.2013047004322

[32] Schwendicke F, Dorfer CE, Schlattmann P, Foster Page L, Thomson WM, Paris S. Socioeconomic inequality and caries: a systematic review and meta-analysis. J Dent Res 2015; 94:10-8. https://doi.org/10.1177/0022034514557546

[33] Tomazoni F, Vettore MV, Mendes FM, Ardenghi TM. The Association between sense of coherence and dental caries in low social status schoolchildren. Caries Res 2018 25; 53(3):314-21. https://doi.org/10.1159/000493537

[34] Ortiz AS, Tomazoni F, Knorst JK, Ardenghi TM. Influence of socioeconomic inequalities on levels of dental caries in adolescents: a cohort study. Int J Paediatr Dent 2019. https://doi.org/10.1111/ipd.12572

[35] Finlayson TL, Siefert K, Ismail AI, Sohn W. Maternal self-efficacy and 1-5-year-old children's brushing habits. Community Dent Oral Epidemiol 2007; 35(4):272-81. https://doi.org/10.1111/j.1600-0528.2007.00313.x

[36] Vann WFJr, Lee JY, Baker D, Divaris K. Oral health literacy among female caregivers: impact on oral health outcomes in early childhood. J Dent Res 2010; 89(12):1395-400. https://doi.org/10.1177/0022034510379601

[37] Peres MA, Macpherson LMD, Weyant RJ, Daly B, Venturelli R, Mathur MR, et al. Oral diseases: a global public health challenge. Lancet 2019; 394(10194):249-60. https://doi.org/10.1016/So140-6736(19)31146-8

[38] de Amorim RG, Figueiredo MJ, Leal SC, Mulder J, Frencken JE. Caries experience in a child population in a deprived area of Brazil, using ICDAS II. Clin Oral Investig 2012; 16(2):513-20. https://doi.org/10.1007/s00784-01 1-0528-9

[39] Guedes RS, Ardenghi TM, Piovesan C, Emmanuelli B, Mendes FM. Influence of initial caries lesions on quality of life in preschool children: a 2-year cohort study. Community Dent Oral Epidemiol 2016; 44(3):292-300. https://doi.org/10.1111/cdoe.12217

[40] Guedes RS, Piovesan C, Ardenghi TM, Emmanuelli B, Braga MM, Mendes FM. Presence of initial caries lesions as a risk factor for caries in preschool children: a cohort study. Caries Res 2018; 52(1-2):32-41. https://doi.org/10.1159/000479824 